\title{
NOTAS
}

\section{Caracteres Demológicos en Mulata de Tal}

Tazol, el primero de los nombres del demonio que aparece en la no. vela de Miguel Angel Asturias Mulata de Tal, es una variante fonética del Tlazol azteca. ${ }^{1}$ En el origen parece que se trata del dios Tlazoltecoatl descrito por Francisco Javier Clavijero como "el dios de la basura, invocado para evitar la infamia que pudieran ocasionar las culpas". Antonio Morales Gómez describe a Tlazoltecoatl como una cierta "Venus impúdica" que presidía la vida de los mexicanos desde las doce del día hasta la una y media de la tarde "por ser ésta la hora del pulque". ${ }^{2}$ El Códice Borgia representa a Tlazoltecoatl como una mujer desnuda que lleva delante un niño en un carrito y parece sostener en la mano a la altura de la boca una serpiente. ${ }^{3}$

Miguel Angel Asturias describe a Tazol como un demonio masculino que "hace pecar a las mujeres". Su aparición es como una "manotada

1 El cambio Tlazol Tazol parece que tiene lugar por absorción de la $L$ a partir del canon de combinación fonética azteca $\mathrm{CCV}$ para conformarse con el canon combinatorio español CVC (consonante-vocal-consonante). Un fenómeno semejante ocurre en la voz sinsonte a partir del mex. centzontle.

2 Francisco Javier Clavijero, Historia Antigua de México (México, 1958), II, p. 81. Antonio Morales Gómez, El Tlilmatl o Libro de los Dioses (Ḿ́xico, 1944), p. 57. Bartolomé de las Casas dice a este respecto: "Tenían otra diosa los mexicanos y los de sus comarcas, de otra calidad que la ya dicha, de la cual dicen o fingen que una vez se les tornaba culebra, y afírmase por cosa notoria; otras veces se les transfiguraba en una moza muy hermosa y andába por los mercados enamorándose de los mancebos y provocándolos a su ayuntamiento, el cual cumplido los mataba. Y esto puede ser verdad de historia y que el demonio usase con aquella gente de tantos engaños..." Apologética Historia (Madrid, 1958), p. 422. ferimos.

3. Morales Gómez trae en el libro citado (p. 272) la imagen a que nos re- 
-o guacalada - de viento" o como una "lluvia — rociadura - de agua de perlas". Es invisible, pero tiene "el peso de una red cargada de hojas de maíz", o sea de tazol, de donde parece que le viene el nombre. Habla con Celestino Yumí, ${ }^{4}$ el indio leñatero que fue a las ferias de San Andrés Milpas Altas, de San Antonio Palapó y de San Martín Chiles Verdes con la bragueta casi abierta para "complacer a Tazol". Su plan parece que era cumplir los deseos de Tazol para que, en cambio, le diera riquezas. Para este fin, el demonio Tazol pide al indio Celestino Yumí que le entregue a su esposa Catalina Zabala porque "le ha faltado" con el compadre Timoteo Teo Timoteo, según lo puede comprobar el indio con "la piedra que habla". Los dos cierran el trato y Tazol se lleva a la Zabala envuelta en una gran "guacalada de viento". Después de esta típica transvección, Celestino, sin su esposa, se siente desesperado de soledad. Pretende ahorcarse como Judas, pero en el momento de echarse la cuerda del suicida se le aparece Tazol en forma de un gran pajarraco que habla y. le da el secreto de la riqueza en una "caja de juguetes de Navidad". En ella hay caballos, vacas, toros, terneros, árboles, hojas de maíz, puentes, canales, corrales, gallinas, gallos y una pastorcita de trenzas negras. A medida que el indio Celestino Yumí saca "juguetes de hombre" de la caja de Tazol se vuelve más rico que su rival el com. padre Timoteo Teo Timoteo que parece representar al hombre dos veces temeroso de Dios. Complacido por esa aventura crematística el indio afirma que "Ia tierra produce cuando está abonada de magia".

La desgracia de Yumí empezó cuando se encontró con la Mulata, la mujer lunar, de doble sexo, que incendia las riquezas del esposo bígamo en un delirio sicadélico. Celestino decide entonces sacar de su caja de juguetes de hombre a la pastorcita Catalina Zabala, la Catocha o la Niniloj como là llaman cariñosamente. Al contrario de los demás "juguetes de hombre" que se multiplican cuando el indio los saca de la caja de Tazol, la Catalina Zabala queda en forma de una enanita minúscula a la que viste de colores la Mulata y la llama Lili Puti o Juana Puti. Cuando la enanita se da cuenta de la degradación de la Mulata con su exesposo la encierra en la Cueva del Pájaro Enojón, en compañía de un oso. La Mulata regresa en un horrible terremoto. Los billetes de banco de Yumí se convierten en "hojas de maíz seco", "basura de hojas de

4 Yumi parece una variante fonética de Cbumi (laba) una de las tribus Quichés. Cf. Delia Goetz and Sylvanus G. Morley, Popul Vub (University of Oklahoma Press, 1950), p. 69. Tal vez el nombre de la tribu Quibaba se relacione con el nombre Quiavicús, el lugar en que vivía Celestino Yumi con su mujer.

5 Zabala parece Chuvilá, el nombre de la ciudad quiché a la que los mexicanos Ilamaron Chichicastenango, en Guatemala. 
maíz", o sea tazol. El embrujo diabólico parece destruido por el regreso a la realidad.

Celestino y su esposa Catalina deciden regresar a su pueblo Quiavicús para seguir el oficio de leñadores. Pero notan que los árboles se les han vueltos humanos. Una noche ven a los "Salvajos", los hombres que Tazol llevó al monte y convirtió en jabalíes cuando bailaban borrachos cubiertos con pieles de jabalí. Los Salvajos dan a Celestino Yumí el secreto para volver a su esposa a la estatura normal. Cambian el nombre de Yumí en Jayumijajá y el de Zabala en Jazabalajajá. En este momento entra en la novela un nuevo mito.

Cumpliendo las instrucciones de los Salvajos el Jayumijajá se encamina a las nueve "vueltas del Diablo" donde apareció el demonio Cashtoc y convirtió a Felicito Piedrasanta, que andaba borracho, en una roca, la Roca del Demonio. Cashtoc es el inventor del aguardiente de caña y está acompañado de la Lechuza o Tucur y de los Siete Buhos. Es el demonio de "la tierra colorada" y se lo llama el Inmenso, el Poderoso Caxtoc. ${ }^{6}$ Ahora se trata para Celestino de "poderle a Tazol". Cuando el demonio de la roca -o el "vueltero del demonio" o sea Felicito Piedrasanta convertido en el "demonio del lugar" - se levanta del suelo con la Zabala a la espalda entonces el indio Yumi, instruido por los Salvajos, retiene a su esposa por los pies hasta hacerla recuperar la estatura normal y soltarse de la espalda de la roca. Este mito de "la mujer pegada a la roca" tiene originalidad. Para crecer la mujer necesita desprenderse de donde está. Celestino Jayumijajá y Catalina Jazabalajajá huyen hacia Tierrapaulita," "el tenebroso reino de la magia negra". Peto Catalina no se ha desprendido de Tazol. Lo lleva "preso" en una cruz de hojas de maíz que carga sobre el pecho. El demonio Tazol está aprisionado en la Cruz, hecha de tazol. El autor aclara en este punto que los granos de maíz

${ }^{6}$ Casbtoc o Caxtoc parece derivarse por mezcla de dos palabras quichés, Cabauil, el nombre genérico de dios, y Xtoc, el nombre de la divinidad de la tierra, particularmente de la agricultura. Tucur, la Lechuza, es el nombre de los mensajeros de Xibalbá, la región subterránea, habitada por los malvados. Tucur es también el nombre del pueblo de Verapaz, en Guatemala. Los Tucures son cuatro: Chabi-Tucur, o la lechuza ligera; Huracán-Tucur, o la lechuza de una pata (La Patasola) gigantesca; Caquix-Tucur, o la lecbuza papagayo y HolomTucur, la lechuza cabeza (el Cabezón) [Cf. Goetz and Morley, op. cit. p. 112]. Es notable que Cashtoc tenga símbolos nocturnos. Parece que es el demonio de las tinieblas.

7 El nombre de Tierrapaulita parece que es un nombre eufemístico por Tierramaldita. El autor hace también con este nombre un juego de palabras en que parece sugerirse el nombre de Guatemala. Sin embargo, este nombre, según unos parece derivarse d Quauhtlemallan que significa "tierra abundante en árboles" Cf. Goetz and Morley, op. cit. p. 77. Según Miguel Angel Asturias Guatemala significa "la tierra de las águilas cautivas". Se deriva del vocablo $Q u a c$ temallan $\mathrm{y}$ hace referencia al escudo de los señores Cakchiqueles. 
son el dios (Tlazoltecoatl) y las hojas de maíz o tazol son el demonio. Aparece aquí la idea del demonio como lo inútil de la existencia humana.

Tierrapaulita es "la tierra de las polvaredas de hueso de muerto, de pelos de ajusticiado, de hojas de vuelveteloco, de cornamentas de toro negro, de pieles de serpiente con humedad de luna por dentro y escamas de sol por fuera". Es "una ciudad caída del cielo como una dentadura vieja". Allí el Tiopagrito (el cura) estaba sitiado por el demonio Cash. toc. En ese paraje extraño tiene lugar la copulación umbilical de Tazol con Catalina Jazabalajajá que desde ese momento tiene pies monstruosos de doble talón para que nadie descubra hacia dónde camina. ${ }^{8}$ Cashtoc le cambia el nombre de Catalina por el de Giroma que quiere decir "la madre de las magias". ${ }^{9}$ Tierrapaulita es también la tierra de los gigantes de Cashtoc, el Huracán o gigante de los vientos; Cabracán o gigante de los terremotos; Zipacná y Chiltic, ${ }^{10}$ o sea Celestino Yumí, convertido primero en enano por la Giroma, luego cambiado en un gigante de Zancos por Tazolito, el hijo de Tazol y la Giroma. Tierrapaulita está habitada por diablos carniceros y diablos matarifes. Hay caracoles de grandes orejas y palmetas que bailan como Salomé. Con ellos está el numeroso "diablerío de servicio", como los Cadejos, los Sisimites, las Lloronas de cabellos de Agua, las Siguamontas o genios femeninos de la selva; las Siguanabas o genios de los barrancos; (los) las Siguapates, o genios de los árboles, los popiques, los malinalis, ${ }^{11}$ los coleletines, los chimanes (shama-

8 Tiopagrito parece una amalgamación de Tio padrecito. Los nombres $Y a-$ yumijajá y Jazabalajajá parecen nombres ecoicos sacados de los nombres Yumí y Zabala con sílaba inicial y doble final Ja, tomada de Jabalí, el animal en que fueron cambiados los Salvajos. Si se tiene en cuenta que Yumí es una variante de Cbumilabá se tendrá otra clave para ver la relación de los nombres novelescos con los lugares y las tradiciones quichés que son la base de la terminología empleada por Miguel Angel Asturias en Mulata de Tal. Como término semejante, especialmente para Jazabalajajá, se tiene el de Comibá, la esposa de BalamAcab. Según Francisco Ximénez, la sílaba ba parece significar agua. Cf. Historia de los indios, de Guatemala. Baca, en el Chilam Balam de Cbumayel viene de bac-baa, echar agua, según Ralph L. Roys. Cf. The Book of Cbilam Balam of Chrimayel, published by Carnegie Institution of Washington, Nov. 1933, p. 71.

- Giroma parece derivarse de Quiroma(ncia), palabra de origen griego que designa una clase particular de magia o adivinación basada en las manos. GirónGagal, en lengua quiché significa regalo o donativo.

${ }_{10}$ Los cuatro gigantes mencionados en el Popol Vub son Huracán, que es el corazón del cielo; Caculbá, el rayo; Cabracán, el terremoto; y Zipacná, "el gigante que lleva las montañas a la espalda". La palabra Chiltic designa el baile de los zancos. Por otra parte, cuatro es un número mágico para los quichés. Designa las cuatro regiones (o cuatro puntos cardinales). Cf. Popol Vub y el Chilam Balam de Cbumayel.

${ }_{11}$ Cigua (cihuatl) en lengua azteca significa mujer. La Siguamonta es tal vez la Ciguamontes o la mujer de los montes (La Madremonte); Ciguanaba es la mujer de los barrancos; Ciguapate es la mujer de los árboles venenosos o medicinales (patli, medicina). Es, además el nombre de un árbol. Malinalli, se- 
nes),,$^{12}$ los Hietberos que saben las fórmulas mágicas y el sacristán que ayuda al Tiopagrito a introducir un "contrabando" de agua bendita encerrado en unos cocos. Pero Cashtoc se apodera de los cocos y, ayudado del Hierbero, los cambia en lox o sexos femeninos. El Tiopagrito se desespera y corta la cabeza del Bautista que el chimán lleva al devorador de cabezas, llamado Cal-cuj, para que devuelva la mano que perdió el sacristán en la lucha contra los cocos. Mientras tanto los gigantes bailan la danza del Cux y del Iboy. ${ }^{13}$ En ella Tazolín mata de una pedrada (como David) a su padre, el gigante de los Zancos, Chiltic. Tierrapaulita termina como un campo de Agramante en donde los santos quedan con cabezas de animales y el demonio Cashtoc se retira porque sabe que va a llegar a Tierrapaulita el Demonio Cristiano. ${ }^{14}$

La fábula de esta primera parte de la novela parece justificada por e] autor en el relato que el viejo cura lleva al obispo. En consecuencia, el su. perior eclesiástico nombra al padre Mateo Chimalpín ${ }^{15}$ como nuevo cura de Tierrapaulita. La misión que recibe es la de combatir al demonio. En tal virtud se lleva unos cuantos libros de demonología y un guante del obispo.

Candanga ${ }^{16}$ es el nombre del demonio cristiano que entra a Tierra. paulita. Es el mismo Lucifer, el Angel Portaluz. ${ }^{17}$ Es anunciado por otro

gún Clavijero, es "cierta hierba" y el nombre de un día del mes. Cf. Clavijero, Op. cit. p. 130. Francisco J. Santamaría, Diccionario de mexicanismos (México, 1959).

${ }_{12}$ Cf. Mircea Eliade, Shamanism (London, 1964) p. 331.

13 El Popol Vub menciona cinco danzas ejecutadas por dos hombres "de humilde apariencia". Estas danzas eran la del pubuy, o de la lechuza cornuda; la del cux, o de la comadreja; la del iboy, o del armadillo; la del xtzul o del ciempiés y la danza del chiltic o de los zancos. Estas danzas fueron ejecutadas "en presencia de los señores de Xibalbá". C. Goetz and Morley, Op. cit. p. 156. Parece que estas danzas tenían carácter shamánico. Cf. Eliade, $O p$. cit.

14 El concepto de Demonio Cristiano pertenece a la Patrología. Parece que fue introducido originalmente por los anacotetas del desierto de la Tebaida en Egipto, especialmente en la Vida de San Hilario escrito por San Jerónimo en la que se describe al demonio que aparece con caracteres de alucionaciones sexuales. Este concepto del demonio (cristiano) fue "legalizado" en el Concilio de Toledo en el año 447. En la Vida de San Antonio el demonio aparece como un negro, joven o viejo, tiene patas de asno, o de oso, o de escorpión. El demonio que atacaba al ermitaño "cambiaba de forma" y "se anunciaba por grandes gritos".

15 Chimalpin parece hacer referencia a los Anales de Chimalpabin en los que se describe la región de Nenoualca y habla de un grupo de Toltecas (Tultecas) "que se fueron hacia el sur hasta Huatimala" Cf. Goetz and Morley $O p$. cit. p. 65 .

16 Candanga es un nombre popular para designar al demonio. Por la terminación parece rélacionarse con ciertos nombres festivos usados en Latinoamérica como pachanga, burundanga, fritanga. Don Tomás Carrasquilla emplea la voz querendanga para designar amores frívolos. Cf. La Marquesa de Yolombó. Por este medio podríamos suponer que Candanga venga de candar, palabra que significa cerrar. El Candanga vendria a ser el cerrado, o el encerrador del infierno.

${ }_{17} \mathrm{La}$ identificación de Candanga con Lucifer, el nombre de los escritores 
demonio, Avilantaro, y tiene por símbolo un gallo. Como "demonio del cielo" se contrapone a Cashtoc que es el demonio de "la tierra colorada". En contra de Cashtoc que destruye a los hombres "hechos de maiz", Candanga busca la reproducción sin límites del hombre "hecho de ba. rro"18 El propósito que lo anima es llenar de condenados el infierno. Por esta razón entra a Tierrapaulita al grito de "Al engendro". Cashtoc es el "gran Equivocista" que hace a los hombres "jugadores de palabras" que se cambian de nombres continuamente. Candanga es el sabelotodo, el "Perilustre", "el Ambidextro", el "Manofacero". Entre Tazol y Cashtoc parece haber una relación de subordinación; entre Candanga y Cashtoc no parece que haya otra relación que la de rivalidad. Así como Tazol coopera con Cashtoc, así Candanga tiene su cooperador en el Mandinga ${ }^{19}$ el diablo alegre que entra rodeado de "negras chulísimas".

El clímax de la acción fabulosa se presenta cuando las dos grandes potestades diabólicas se unen en matrimonio. En efecto, para aceptar el reto del padre Mateo Chimalpín Candanga se encarna en el indio leñador Celestino Yumí; Cashtoc se transforma en La Mulata y se encarna en el sacristán Jerónimo de la Degollación de San Juan Bautista por Herodes Antipas. En realidad parece que se trata de un estudiante de medicina fracasado que viene a Tierrapaulita con el padre Chimalpín. Por esa extraña encarnación de La Mulata y del demonio, el sacristán tenia "ojos de luna" y ademanes de "señorita vieja". Celestino Yumí, que pasa a llamarse José Quinquín, dice al cura que el demonio de Tierrapaulita es el demonio de los once mil cuernos. Para vencerlo necesita once mil brazos. Y al momento se transforma en "una ataña tonsurada" de once mil manos. Sube al altar a decir una misa de difuntos que es a la vez una misa de esponsales porque en ella el Demonio Cristiano, Candanga o Celestino Yumí o José Quinquín se une a la Mulata de Tal que es Cash. toc, desprendido del Sacristán. En esta forma extraña se repite en esta novela americana la leyenda europea de la "misa negra".

Del cuerpo tatuado de viruelas de Celestino Yumí salen miles de

patrísticos para designar al ángel malo antes de la caída, está en relación con el nombre anterior que le dio el autor, el Demonio Cristiano. Es un demonio aéreo, en lo cual parece relacionarse con la segunda jerarquía de Guazzo. Cf. Compendium Maleficarum (London, 1919). En cambio, Cashtoc es un demonio terrestre, o de tercera categoría.

18 En la leyenda quiché los hombres fueron hechos primero de tierra (Popol $V u h$, parte I, cap. 2); luego de manera (Ibidem); finalmente fueron hechos de maiz blanco y amarillo (parte III, cap. 1 ).

19 Mandinga es otro nombre popular para el demonio. Parece un eufemismo por el Maldito. En el lenguaje hipocorístico se emplea mandisga por astuto en algunas regiones de Colombia. Sin embargo, Mandinga parece tomado del nombre de una tribu del Congo. 
tirabuzones de sensualidad que lo convierten en un Puerco Espín. En pre. sencia de Miguel Santano, el farmaceuta que ha venido en ese Viernes Santo a adorar al Maladrón por su librepensamiento, el padre Mateo Chimalpín persigue al demonio Puerco Espín. Lo que Santano ve es "una araña tonsurada" que lucha con un animal cubierto de espinas. Mientras tanto viene la Giroma, acompañada de la Huasanga, ${ }^{20}$ la bruja robadora de sexos femeninos. La Mulata, despojada de su sexo, es llevada a La Cueva de los Pedernales donde le quita la mitad del cuerpo. Pasa al patio de los Malenos, muñecos maléficos toscamente tallados; llega al Patio de los Intérpretes. Allí se cambia en Yapolí Icué:21 Se viste de Tipumalona, la mujer del demonio Tipumal, que se baña en pozos de vapor. ${ }^{22}$ Arroja sobre Celestino Yumí "la neblina de la luna" que lo endurece como piedra. El leñador queda paralítico. A Miguel Santano se lo lleva el demonio. Oye en el infierno la historia de la caída del cielo del Angel Portaluz porque encontró una planta inteligente, el tabaco y Dios, que aparece como un anciano conservador, lo lanza "a la tierra". Allí se encuentra con los gigantes (descritos en el Popoll Vub) Huracán, Cabracán, Zipacná, a quienes maneja el poderoso Cashtoc. Candanga se junta con Cashtoc y con los demonios de piedra blanca a "fumar el puquiete". Discuten sobre la creación de Eva de una costilla de Adán en lugar de haber sido hecha de una voluta de humo de tabaco. Hablan del descubrimiento de América que "convirtió al hombre en un zancudo ansioso de humo tóxico". Candanga, dueño de Tierrapaulita, quiere convertir ese lugar en un criadero de gente sin control para así "repoblar el infierno". En consecuencia, Santano quiere comprar un seguro de fuego eterno para asegurarse de que el infierno nunca se acabará. Esta parte de la novela presenta una curiosísima teurgia en la que se mezclan dogmas religiosos, referencias a la tecnología moderna, costumbres sociales y prácticas co. merciales. Candanga, el Portaluz, el Manofacero es descrito como el genio del progreso humano que es un flatus vocis, polvo de las palabras de Candanga.

20 Huasanga es un nombre similar en la terminación a Candanga. Podtia ser el nombre del genio diabólico femenino correspondiente.

21 Xpuch era la doncella quiché que trató de tentar a Tohil cuando se banaba (Popol Vub, parte IV, cap. 2). Xquic era la hija del señor de Xibalbá y madre de Hunaphú y Xbalanqué. (Popol $V u b$, parte II, cap. 3). Yapolí Icué podría venir de estos nombres. İcue en azteca significa doncella. Chalchibuitlicue era el nombre de la cloncella del agua, compañera de Tlaloc. Of. Clavijro, p. 74.

22 Tipu es un lugar de Honduras Británica.

El baño en pozos de vapor está descrito por Clavijero quien los llama temas. cales o hipocaustos. Cf. Historia Antigua de México t. II, pp. 323-325. Para Mircea Eliada estos "baños de vapor" eran práctica característica del shamanismo Cf. Mircea Eliade, Sbamanism (London, 1964) p. 331. 
El padre Chimalpín cae enfermo de viruelas. Hace llamar al médico, pero el sacristán le trae al curandero Zac Mucunuy o Mucunuy Quim que ensaya en el levita "la cura de la doncella con sarpullido" y "la monta en la Mula Carnívora". Esa "doncella con sarpullido" está en la casa de la Tintorera, la bruja que sabe el secreto de la Mulata, el "mito de la luz lunar que vuelve a los hombres piedra". Recita la fórmula shamánica para extraer el mal de los cuerpos. En ese momento se oye el grito de Candanga, el Tentador Cristiano: "Al engendro". El mundo se sacude en un paroxismo macabro en que el sacristán anda desnudo con una sábana, el padre Chimalpín vuela montado en la Mula Carnívora como el apóstol Santiago en su caballo ${ }^{23}$ y la Multada es el disco lunar que chocó contra la Sierra Madre de donde saltó el fuego blanco según la leyenda quiché (o Xalil). ${ }^{24}$ Los símbolos oníricos tan manifiestos en esta parte de la fábula novelesca parecen tomados del delirio de la viruela del padre Chimalpín.

En consecuencia, parece que la concepción demonística que presenta Miguel Angel Asturias en Mulata de Tal se podría reducir a tres caracteres centrales. El primero en orden de presentación es Tazol, el demonio de la riqueza fatua que se representa en las hojas verde-amarillas que cubren los granos de maíz. En este mito el hombre está hecho de maíz y está destinado "a vivir en sociedad". Corresponde al concepto de "la concupiscencia de los ojos o de la riqueza" que enseñaron los antiguos moralistas. El segundo carácter demonístico es Cashtoc, el Grande, e] Inmenso, el demonio del poder destructor del hombre, que maneja los gigantes enemigos de la vida sobre la tierra, como el Huracán y el Ca. bracán o gigante de los terremotos. Tiene su equivalente en la "concupiscencia de la vida" de los predicadores cristianos. Finalmente, Candanga es el demonio de la carne, del placer del sexo y del tabaco. La civilización parece estar al servicio de este demonio. La secuencia riquezas, orgullo y placeres parece también tener especial significación en la estruc. tura de la novela. La primera escena parece tener resonancias de las ideas

23 La primera ciudad de Guatemala fue puesta bajo la advocación del Apóstol Santiago por haber sido fundada el 25 de Julio día en que la Iglesia Católica celebra la festividad de este santo. El paralelismo entre el Apóstol Santiago montado en un caballo blanco y el Padre Chimalpin montado en La Mula Carnívora, la bestia que "entiende las palabras" parece sugetir el dominio sobre "las pasiones animales".

24 El mito lunar encarnado en Mulata de Tal es una de las características sobresalientes de las religiones aztecas, maya y quiché. Daniel G. Brinton trae una cita del autor alemán Buschman (Spuren der Aztekischen Sprache im Nördlichen Mexico) en que relaciona el nombre de la luna Metzli con las palabras miqui, morir, micqui, muerto, mictlan, el reino de la muerte, te-miqui, soñar y cec-miqui, congelarse. Cf. The Mytbs of the New World (New York, 1969) p. 139. 
de Bernard Mandeville según aparecen en el libro La Fábula de las Abe. jas, escrito en 1714. Parece querer decir que "Ios placeres son la fuente de la riqueza". La segunda parte presenta al demonio de la conquista. Pero afirma que "conquistar es destruir". El demonio de la conquista es "el demonio destructor del hombre". La última parte parece ofrecer una sátira de la "explosión demográfica" de América Latina.

El contenido demonológico de procedencia europea expresado en Mulata de Tal es considerable. Nos encontramos en esta novela con un pacto con el demonio en forma un tanto atenuada y no tan pública $y$ solemne como los pactos descritos por Francisco María Guazzo; tranvec. ciones semejantes a las referidas por Juan Bautista Porta; relaciones sexuales con el demonio como las explicadas por Ludovico María Sinis. trari en 1701; una misa negra que tiene referencias a la descrita por el Marqués de Sade en Justine; demonios en figura de animales como los "familiares" descritos por Mathew Hopkins; encantamientos y fórmulas mágicas de curación. ${ }^{25}$ El Candanga y el Mandinga parecen derivados de concepciones demonísticas afro-americanas. El demonismo auténticamen. te americano parece contenido en los gigantes quichés Huracán, Cabracán y Zipacná tomados del Popul Vub; en los números mágicos cuatro, siete y nueve del Chilam Bilam y del Popol Vub; en los mitos aztecas. mayas-quichés del Tazol; en el nahualismo mexicano-quiché; en las leyen. das mexicano-guatemaltecas de la Siguamonta, la Siguanaba, el Sisimite y el Sombrerón que se han extendido hacia Suramérica con los nombres de la Madremonte, la Gritona y el Sombrerón y las leyendas guatemaltecas del Cadejo, la Tatuana y las Tipumalonas. Parece que en estos tipos y leyendas se encarnan algunas concepciones características de la fantasía indohispánica que trascriben una cierta conciencia del mundo primitivo o tal vez la fabulación semiconsciente del mundo sentido pero no del todo comprendido. En este sentido parece adivinarse algo de la cosmología mítica de Centroamérica en Mulata de Tal con lo cual vendrá a justificarse la alusión a "un fondo más metafísico" en el tratamiento de las leyendas de Guatemala, según dice por A. Dessau. ${ }^{26}$

En el aspecto literario conviene notar la abundancia de metáforas con contenidos mágicos que hacen de la lectura de Mulata un continuo cosquilleo de la fantasía. Las palmeras son "cuerpos de Salomé" o "manos

25 Francesco Maria Guazzo, Compendium Maleficarum (London, 1929). Johanes Baptista Porta, Natural Magic (London, 1658). Ludovico Maria Sinistrari, De Daemonialitate et Incubis et Succubis (Paris, 1875). Matthew Hopkins, The Discovery of Witches (London, 1928).

26 Kurt L. Levy y Keith Ellis, El Ensayo y la Crítica Literaria en Iberoamérica (Toronto, 1970) p. 213. 
de múltiples dedos verdes"; la sangre es "bartedura de silencio"; el silencio es "polvo de sonido"; la tierra es un "horno uterino"; el sexo es "una estrella-serpiente"; los hombres son fotografias, porque "primero fue una cámara oscura, luego un disparo sobre una placa sensibilizada y finalmente la imagen de un nuevo ser"; el agua es "una culebra líquida"; el cielo azul es "una pizarra limada"; el tabaco es "la teta de una mujer de humo"; las palabras son "alquitrán de tiniebla" y la imaginación que produjo estas figutas retóricas es "la hija del demonio". "En esta serie de metáforas inusitadas se transparenta el talento, tal vez el genio crea. dor de Miguel Angel Asturias, adobado con larga dosis de lecturas de los libros quichés y Xalil.

Luis PÉrez Botero

University of Saskatchewan

Saskatoon, Canada 